\title{
Efficacy of Intra-Articular Hyaluronic Acid and Cortisone Compared to Cortisone alone for Symptomatic Hip Osteoarthritis
}

Paul Crook ${ }^{1^{*}}$, Jay Shah ${ }^{2}$, Kory Lee ${ }^{3}$, Gaurav Synghal ${ }^{3}$, Rayce Yanney ${ }^{3}$, Joshua Rollins ${ }^{3}$, Brandon Couch ${ }^{3}$, Matthew Nickell ${ }^{3}$, Lowell Rollins ${ }^{3}$, Alex Kreines Do and Mark Adickes MD

${ }^{1}$ Department of Orthopaedic Surgery, Baylor College of Medicine, Houston, TX, USA

${ }^{2}$ University of Texas Southwestern Medical Center at Dallas, Dallas, TX, USA

${ }^{3}$ University of Texas Health Science Center at Houston, Houston, TX, USA

"Corresponding author: Paul Crook, 3 Hermann Museum Circle Drive, Apt 2312, Houston, TX, USA 77030, Tel: 615-293-2602; E-mail: Paul.davidson.crook@gmail.com

Received date: December 31, 2018; Accepted date: February 11, 2019; Published date: February 18, 2019

Copyright: (C) 2019 Crook P, et al. This is an open-access article distributed under the terms of the Creative Commons Attribution License, which permits unrestricted use, distribution, and reproduction in any medium, provided the original author and source are credited.

\section{Abstract}

Background: Viscosupplementation through intraarticular injection of hyaluronic acid (HA) has shown beneficial effects in the treatment of hip osteoarthritis. Cortisone injections for have also been shown to alleviate symptoms in hip osteoarthritis. While studies in knee osteoarthritis have shown the safety and synergistic effect of a combination $\mathrm{HA}$ and cortisone injection, there have been no studies on the use of a combination HA and cortisone injection in the hip.

Hypothesis: The purpose of this study is to determine the efficacy of a combination of intra-articular HA and cortisone when compared to cortisone alone in the treatment of symptomatic hip osteoarthritis.

Study design: Case- control study

Methods: All hip injections for osteoarthritis carried out from January 2009 to December 2014 were retrospectively reviewed. Pain severity using the numerical rating scale and osteoarthritis severity using the Tonnis classification were recorded for each patient. All injections were performed with fluoroscopic guidance and patients received either cortisone or a combination of cortisone and $\mathrm{HA}$.

Results: 119 patients who received cortisone alone were matched 1:1 with respect to age, gender, BMI, and diagnosis with 119 patients who received cortisone and HA. Mean duration of follow up was 26 months. Median duration of pain relief was 32.3 days in the cortisone group and 128.6 days in the cortisone plus HA group $(p=0.000001)$

Conclusions: This is the first study to evaluate the efficacy of a combination injection of intra-articular hyaluronic acid and cortisone in hip OA. While no difference in post injection pain relief when compared to cortisone alone was noted, there was a significant difference in the duration of pain relief with the combination providing more than 3 additional months of relief.

Keywords: Hip; Pain management; Anesthesia; Biologic healing enhancement

\section{Introduction}

Osteoarthritis $(\mathrm{OA})$ of the hip is a frequent cause of pain, disability and has significant social and economic impact [1,2]. Conservative treatment of $\mathrm{OA}$ includes activity modification, weight loss, physical therapy, non-steroidal anti-inflammatory medications (NSAIDs), Acetaminophen, physical therapy as well as intra-articular injections [3-7].

Intra-articular injections of the hip are typically performed for diagnostic and/or therapeutic reasons. For diagnostic purposes, an intra-articular anesthetic can be beneficial to distinguish symptomatic intra-articular pathology from potential extra-articular sources of hip pain [8-10]. Intra-articular cortisone injection is also commonly used in patients with osteoarthritis of the hip for therapeutic reasons. Studies, however, have demonstrated uncertain efficacy, [11,12] modest improvement [13] insignificant benefit [14,15] and an unpredictable duration of beneficial pain relief [16]. Other studies have demonstrated good efficacy, with 1-2 months pain relief [17-19] While intra-articular corticosteroid injections are described as a low-risk treatment option for those patients with osteoarthritis of the hip, with the need for repeated injections studies have raised concerns of chondrotoxicity $[20,21]$.

Viscosupplementation by intra-articular injections of hyaluronic acid (HA) has shown beneficial effects in the treatment of OA [22]. HA reduces pain associated with $\mathrm{OA}$ by several mechanisms, including inhibition of tissue nociceptors, stimulation of endogenous HA, direct anti-inflammatory effects, and inhibition of matrix metalloproteinase activity [23]. Histological and magnetic resonance studies have also demonstrated a chondro-protective effect $[23,24]$. While a vast 
majority of the literature has focused on HA in knee OA, there has recently been an increase in the number of studies on HA in the hip joint demonstrating its efficacy [1,6,25-32].

The combination of HA and cortisone has been demonstrated to be safe and effective in the knee [33]. Ozturk et al. published their results of a randomized controlled trial of 40 patients with knee osteoarthritis who received either an injection of HA alone or HA plus steroid (triamcinolone) [33]. They reported no progression of osteoarthritis in either group at 1 year follow-up. However, they found that pain decreased more rapidly and to lower levels with the combination injection compared to $\mathrm{HA}$ alone at 1 year follow-up. Grecomoro et al. published similar results in a randomized controlled trial comparing pain relief in knee osteoarthritis patients receiving either HA or combination HA and steroid injections [34]. They also found faster pain relief and lower VAS pain scores in the combination injection group. There have been no studies on the use of a combination of HA and cortisone on the hip. The purpose of the present study was to determine the efficacy of a combination of intraarticular HA and cortisone when compared to cortisone alone in the treatment of symptomatic hip OA.

\section{Methods}

This study was approved by the Institutional Review Board at our institution. All hip injections carried out from January 2009 to December 2014 were retrospectively reviewed. Inclusion criteria for the study included the following: (1) a diagnosis of symptomatic hip $\mathrm{OA}$ and (2) fluoroscopic guided intra-articular injection of corticosteroid. Exclusion criteria included the following: (1) intraarticular injection performed outside of our institution and (2) prior ipsilateral hip surgery. These were then matched in a 1:1 ratio with respect to age, gender, BMI and diagnosis with patients who underwent fluoroscopic guided intra-articular injection of corticosteroid and HA.

Pain severity was evaluated using the numerical rating scale (NRS), which measures pain intensity on a scale from 0 to $10[28,35]$. We considered an absolute change of 2 points on the NRS score, clinically significant pain relief, as previously reported [36,37]. Post-injection pain was recorded as the lowest pain rating in the $24-48$ hours following injection. We also recorded the overall duration of pain relief obtained from the intra-articular injection.

Radiographic assessment including AP, false-profile, Dunn and cross-table lateral radiographic images of the involved hip was obtained prior to the injection. The degree of osteoarthritis was determined for each symptomatic hip utilizing the Tonnis classification $[34,38]$. The grade for each hip was determined based on the individual radiographic view with the highest grade $[34,38]$.

All intra-articular injections were performed by the senior author under fluoroscopic guidance in the operating room under conscious sedation. Following a surgical time-out to confirm the correct patient and operative site, fluoroscopy was utilized to localize the hip joint. Five $\mathrm{mL}$ of $1 \%$ lidocaine was injected into the skin, subcutaneous and deeper tissue on a tract down to the joint. A 22 gauge needle was placed into the joint and an air arthrogram was performed to confirm intra-articular placement of the needle. Two $\mathrm{mL}$ of cortisone (40 $\mathrm{mg} / \mathrm{mL}$ Kenalog, Bristol-Meyers Squibb, New York, NY) was then injected with or without $2 \mathrm{~mL}$ of HA (Supartz, Bioventus, Durham, $\mathrm{NC}$ ). The hip was then taken through a range of motion to allow the injectant to coat the entirety of the articular surface. The procedure was performed in an outpatient setting with instructions to return to full unrestricted activity as tolerated after completion.

All data were summarized and reported using mean (range) for continuous, median (range) for ordinal variables, and count (percentage) for categorical variables, unless otherwise specified. Patient characteristics and pain outcomes were compared between patients receiving cortisone and a combination of cortisone with HA using nonparametric Wilcoxon rank-sum tests for variables measured on a continuous or ordinal scale, and chi-square tests for categorical variables. Pain ratings were evaluated and compared using Friedman's test (a nonparametric analogue to repeated measures ANOVA) and the associated rank- sum multiple comparisons test to identify pair-wise differences while maintaining the overall type-I error rate at 0.05 . All statistical tests were two-sided, and $p$ values $<0.05$ were considered statistically significant. All analysis was conducted using SPSS version 15.0 (SPSS Inc. Chicago, IL).

\section{Results}

From January 2009 to December 2014, 438 hip injections were performed at our institution. After applying inclusion and exclusion criteria, 119 patients were included in the cortisone group. Fifty-five were male (46\%) and 64 were female (54\%). Mean patient age was 50.5 \pm 10.2 years (range 36-75). Mean patient BMI was $25.1 \pm 3.4$ (19.5-35.7) and mean duration of follow-up was $26.4 \pm 15.4$ months (range 6-66). These were then matched in a 1:1 ratio with respect to age, gender, BMI and diagnosis with 119 patients who received a combined HA and cortisone injection (combined group). Fifty-five were male (46\%) and 64 were female (54\%). Mean patient age was 48.7 \pm 9.8 years (range 34-72). Mean patient BMI was $24.7 \pm 3.6$ (20.3-38.9).

The median pre-operative NRS score for the $C$ group was 7 (5-9) and the post-operative score was $2(0-3)$, with the difference being statistically significant, $p=0.0003$. The median pre-operative NRS score for the HA group was 7 (5-10) and the post-operative score was $1(0-4)$, with the difference being statistically significant, $\mathrm{p}=0.00004$ (Figures $1-3)$. The mean duration of pain relief was $32.3 \pm 8.6$ (3-72) days for the $\mathrm{C}$ group and $128.6 \pm 20.3$ (2-184) days for the HA group, with the difference also being statistically significant, $\mathrm{p}=0.000001$ (Figure 4 ).

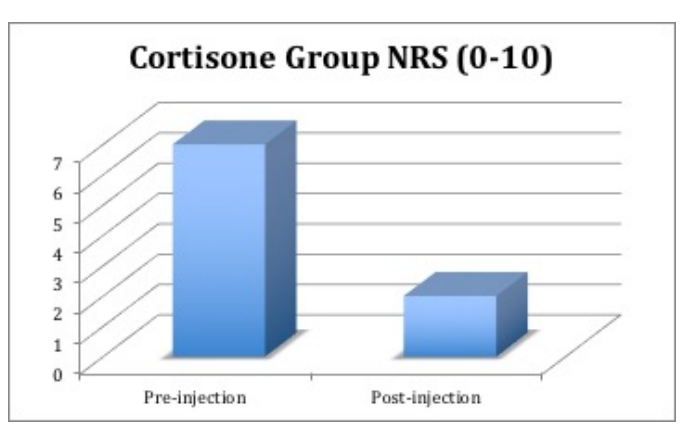

Figure 1: Median pre- and post- injection NRS scores for cortisone group. 
Page 3 of 5

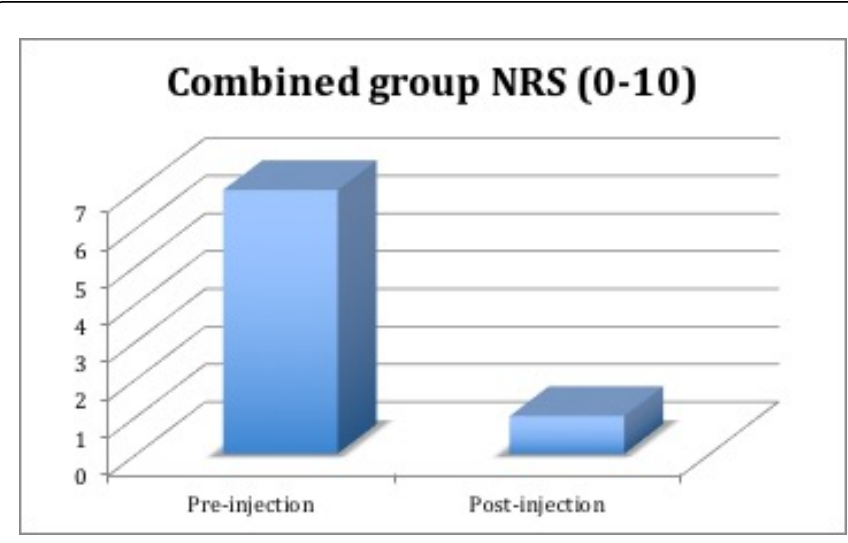

Figure 2: Median pre- and post-injection NRS scores for combined group.

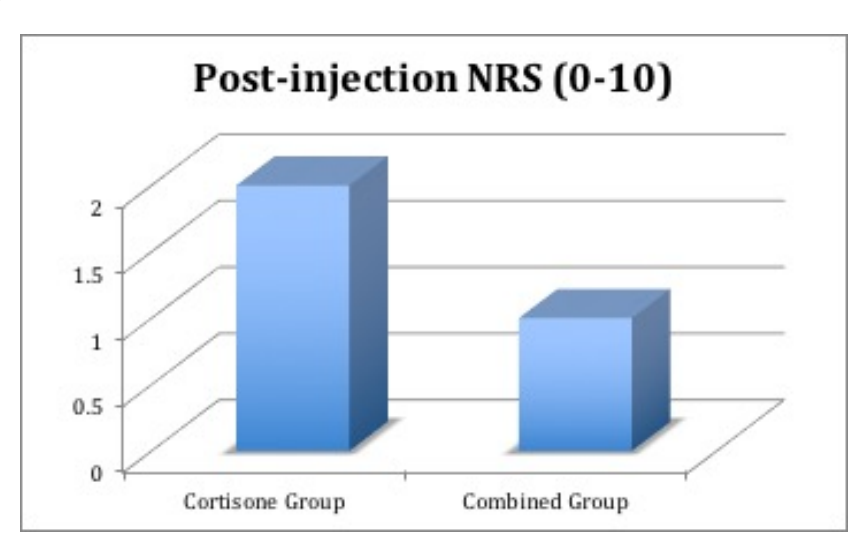

Figure 3: Comparison of post-injection NRS scores between cortisone and combined groups.

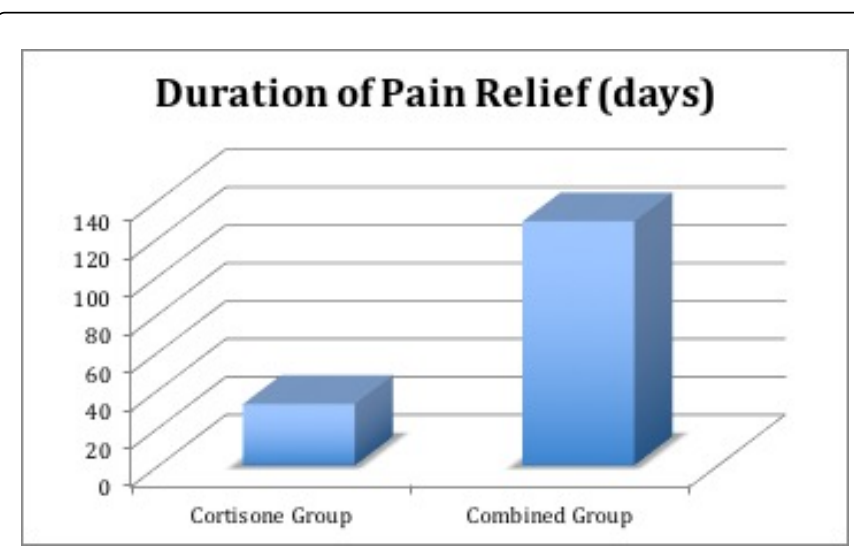

Figure 4: Comparison in duration of pain relief between cortisone and combined groups.

There were no significant differences between the two groups with respect to age, BMI, duration of follow-up, pre-operative or postoperative pain scores $(\mathrm{p}=0.412, \mathrm{p}=0.483,0.0579, \mathrm{p}=0.792, \mathrm{p}=0.195$ respectively) (Table 1$)$.

\begin{tabular}{|l|l|l|}
\hline & Cortisone & HA \& Cortisone \\
\hline Number of Patients & 119 & 119 \\
\hline Mean Age in years & $50.5(36-75)$ & $48.7(34-72)$ \\
\hline Mean BMI & $25.1(19.5-35.7)$ & $24.7(20.3-38.9)$ \\
\hline \% Male & 46 & 46 \\
\hline \% Female & 54 & 54 \\
\hline \% Tonnis 1 & 59.6 & 59.6 \\
\hline \% Tonnis 2 & 23.6 & 23.6 \\
\hline \% Tonnis 3 & 16.8 & 16.8 \\
\hline Mean Follow-up in months & $37.8(6-69)$ & $26.4(6-46)$ \\
\hline
\end{tabular}

Table 1: Comparison of demographic variables between cortisone and combined groups.

\section{Discussion}

This is the first study to evaluate the efficacy of a combination of intra-articular HA and cortisone when compared to cortisone alone in the treatment of symptomatic hip OA. Although we found no statistically significant difference in post-injection pain scores, there was a significant increase in the duration of pain relief for the group that received both HA and cortisone.

Several studies have demonstrated the efficacy of intra-articular cortisone in hip OA. Flanagan et al., Micu et al., Atchia et al., all demonstrated about one month of relief $[14,17,18]$. Robinson et al. were able to demonstrate up to 6 weeks of relief [19]. Results from the present study compare favorably with the literature demonstrating just over 4 weeks of relief for the cortisone group alone.

The efficacy of HA in hip osteoarthritis has also been previously studied. Qvistgard et al., demonstrated about 10 weeks of relief while Milgore et al., and Conrosier et al. both demonstrated close to 12 weeks of relief [6,27]. Spitzer et al., demonstrated almost 16 weeks of relief with course of 3 weekly injections [31]. The present study was able to obtain over 16 weeks of relief from a single injection of a combination of HA and cortisone.

There have been numerous studies of sequential injections and the demonstration of a dose-response curve for HA in the knee with a consensus of 3 week weekly injections of HA providing the maximum benefit $[2,12,30,32,38]$. In the United States, HA is not currently FDA approved in the hip making its use "off-label." This combined with the use of fluoroscopy and OR anesthesia makes it both practically and economically unfeasible to provide serial injections currently. While no such studies are available for the hip, further studies are necessary to determine this dose-response relationship in the hip.

The present study does have several limitations. Retrospective studies introduce inherent selection, recall and treatment biases. In addition the patient population was small and heterogeneous in nature making comparisons difficult even with a control group. Additionally there were no functional scores available for this group of patients. This has been rectified and we have modified our practice to begin collecting these scores prospectively. Additionally the strengths of the study are that the study is adequately powered, a control group was employed allowing for accurate comparisons between groups, and a 
single surgeon utilizing a single technique performed all of the injections.

The implementation of combination HA and cortisone injection compared to cortisone alone could have several positive impacts in the treatment of hip osteoarthritis. In theory, this new treatment may lead to less doctor's appointments and a decreased need for repeat injections as the pain relief is longer. This treatment may also have a secondary economic benefit due to patients not having to miss as many days of work. Finally, our hope is that the increased duration of pain relief from these injections may allow patients to delay surgical intervention, including hip replacement, for their condition.

This is the first study to evaluate the efficacy of a combination of intra-articular hyaluronic acid and cortisone in hip OA. While no difference in post injection pain relief when compared to cortisone alone was noted, there was a significant difference in the duration of pain relief with the combination providing more than 3 additional months of relief. Due to the retrospective nature of the study, further research is needed to determine if these results bear out in doubleblinded prospective randomized controlled trials. Other additional areas of study include establishing a dose response curve and determining if the combination also confers improvement in functional scores.

\section{References}

1. Battaglia M, Guaraldi F, Vannini F, Rossi G, Timoncini A, et al. (2013) Efficacy of ultrasound-guided intra-articular injections of platelet-rich plasma versus hyaluronic acid for hip osteoarthritis. Orthopedics 36: e1501-e1508.

2. Roux CH, Saraux A, Mazieres B, Pouchot J, Morvan J, et al. (2008) Screening for hip and knee osteoarthritis in the general population: predictive value of a questionnaire and prevalence estimates. Ann Rheum Dis 67: 1406-1411.

3. Creamer P (1999) Intra-articular corticosteroid treatment in osteoarthritis. Curr. Opin. Curr Opin Rheumatol 11: 417-421.

4. Gigante A, Callegari L (2011) The role of intra-articular hyaluronan (Sinovial) in the treatment of osteoarthritis. Rheumatol Int 31: 427-444

5. Hochberg MC, Altman RD, Brandt KD, Clark BM, Dieppe PA, et al. (1995) Guidelines for the medical management of osteoarthritis. Part I. Osteoarthritis of the hip. American College of Rheumatology. Arthritis Rheum 38: 1535-1540.

6. Richette P, Ravaud P, Conrozier T, Euller-Ziegler L, Mazières B, et al. (2009) Effect of hyaluronic acid in symptomatic hip osteoarthritis: a multicenter, randomized, placebo-controlled trial. Arthritis Rheum 60: 824-830.

7. Zhang W, Nuki G, Moskowitz RW, Abramson S, Altman RD, et al. (2010) OARSI recommendations for the management of hip and knee osteoarthritis: part III: Changes in evidence following systematic cumulative update of research published through January 2009. Osteoarthritis Cartilage 18: 476-499.

8. Crawford RW, Gie GA, Ling RS, Murray DW (1998) Diagnostic value of intra-articular anaesthetic in primary osteoarthritis of the hip. J Bone Joint Surg Br 80: 279-281.

9. Faraj AA, Kumaraguru P, Kosygan K (2003) Intra-articular bupivacaine hip injection in differentiation of coxarthrosis from referred thigh pain: a 10 year study. Acta Orthop Belg 69: 518-521.

10. Kleiner JB, Thorne RP, Curd JG (1991) The value of bupivicaine hip injection in the differentiation of coxarthrosis from lower extremity neuropathy. J Rheumatol 18: 422-427.

11. Neustadt DH (1997) Local steroid injections: comment on the American College of Rheumatology guidelines for the management of osteoarthritis of the hip and on the letter by Swezey. Arthritis Rheum 40: 1914-1915.
12. Swezey RL (1996) Comment on the American College of Rheumatology guidelines for osteoarthritis of the knee and hip. Arthritis Rheum 39: 2083.

13. Hollander JL (1953) Intra-articular hydrocortisone in arthritis and allied conditions; a summary of two years' clinical experience. J Bone Joint Surg Am 35: 983-990.

14. Flanagan J, Casale FF, Thomas TL, Desai KB (1988) Intra-articular injection for pain relief in patients awaiting hip replacement. Ann R Coll Surg Engl 70: 156-157.

15. Plant M, Borg A, Dziedzic K, Dawes P (1994) Intra-articular steroid injection of the hip improves pain and movement at two weeks but not at three months. Br J Rheumatol 33: 76.

16. Griffith S, Cheung N, Dean T, Jones P, Dawes P (1997) Clinical outcomes: a double-blind randomized controlled trial to compare the effect of intraarticular local anaesthetic and local anaesthetic plus steroid in hip arthritis. Br J Rheumatol 36: 21.

17. Atchia I, Kane D, Reed MR, Isaacs JD, Birrell F (2011) Efficacy of a single ultrasound-guided injection for the treatment of hip osteoarthritis. Ann Rheum Dis 70: 110-116.

18. Micu MC, Bogdan GD, Fodor D (2010) Steroid injection for hip osteoarthritis: efficacy under ultrasound guidance. Rheumatology (Oxford) 49: 1490-1494.

19. Robinson P, Keenan AM, Conaghan PG (2007) Clinical effectiveness and dose response of image-guided intra-articular corticosteroid injection for hip osteoarthritis. Rheumatology (Oxford) 46: 285-291.

20. Braun HJ, Wilcox-Fogel N, Kim HJ, Pouliot MA, Harris AHS, et al. (2012) The effect of local anesthetic and corticosteroid combinations on chondrocyte viability. Knee Surg Sports Traumatol Arthrosc 20: 1689-1695.

21. Dragoo JL, Danial CM, Braun HJ, Pouliot MA, Kim HJ (2012) The chondrotoxicity of single-dose corticosteroids. Knee Surg Sports Traumatol Arthrosc 20:1809-1814.

22. Abate M, Pulcini D, Di Iorio A, Schiavone C (2010) Viscosupplementation with intra-articular hyaluronic acid for treatment of osteoarthritis in the elderly. Curr Pharm Des 16: 631-640.

23. Moreland LW (2003) Intra-articular hyaluronan (hyaluronic acid) and hylans for the treatment of osteoarthritis: mechanisms of action. Arthritis Res Ther 5: 54-67.

24. Reid MC (2013) Viscosupplementation for osteoarthritis: A primer for primary care physicians. Adv Ther 30: 967-986.

25. Abate M, Pelotti P, De Amicis D, Di Iorio A, Galletti S, et al. (2008) Viscosupplementation with hyaluronic acid in hip osteoarthritis (a review). Ups J Med Sci 113: 261-277.

26. Abate M, Scuccimarra T, Vanni D, Pantalone A, Salini V (2014) Femoroacetabular impingement: Is hyaluronic acid effective? Knee Surgery Sport Traumatol Arthrosc 22: 889-892.

27. Fernández López JC, Ruano-Ravina A (2006) Efficacy and safety of intraarticular hyaluronic acid in the treatment of hip osteoarthritis: a systematic review. Osteoarthritis Cartilage 14: 1306-1311.

28. Krych AJ, Griffith TB, Hudgens JL, Kuzma SA, Sierra RJ, et al. (2014) Limited therapeutic benefits of intra-articular cortisone injection for patients with femoro-acetabular impingement and labral tear. Knee Surgery Sport Traumatol Arthrosc 22: 750-755.

29. Lieberman JR, Engstrom SM, Solovyova O, Au C, Grady JJ (2015) Is Intra-Articular Hyaluronic Acid Effective in Treating Osteoarthritis of the Hip Joint? J. Arthroplasty 30: 507-511.

30. Lùrati A, Laria A, Mazzocchi D, Re KA, Marrazza M, et al. (2015) Effects of hyaluronic acid (HA) viscosupplementation on peripheral Th cells in knee and hip osteoarthritis. Osteoarthr Cartil 23: 88-93.

31. Paoloni M, Di Sante L, Dimaggio M, Bernetti A, Mangone M, et al. (2012) Kinematic and kinetic modifications in walking pattern of hip osteoarthritis patients induced by intra-articular injections of hyaluronic acid. Clin Biomech 27: 661-665. 
Citation: Crook P, Shah J, Lee K, Synghal G, Yanney R, et al. (2019) Efficacy of Intra-Articular Hyaluronic Acid and Cortisone Compared to Cortisone alone for Symptomatic Hip Osteoarthritis. J Arthritis 8: 278. doi:10.4172/2167-7921.1000278

Page 5 of 5

32. Spitzer AI, Bockow BI, Brander VA, Yates JW, MacCarter DK, et al. (2010) Hylan g-f 20 improves hip osteoarthritis: a prospective, randomized study. Phys Sportsmed 38: 35-47.

33. Ozturk C, Atamaz F, Hepguler S, Argin M, Arkun R (2006) The safety and efficacy of intraarticular hyaluronan with/without corticosteroid in knee osteoarthritis: 1-Year, single-blind, randomized study. Rheumatol Int 26 314-319.

34. Grecomoro G, Piccione F, Letizia G (1992) Therapeutic synergism between hyaluronic acid and dexamethasone in the in- tra-articular treatment of osteoarthritis of the knee: a preliminary open study. Curr Med Res Opin 13: 49-55.
35. Dawes HN, Barker KL, Cockburn J, Roach N, Scott O, et al. (2005) Borg's rating of perceived exertion scales: do the verbal anchors mean the same for different clinical groups? Arch Phys Med Rehabil 86: 912-916.

36. Farrar JT, Young JP, LaMoreaux L, Werth JL, Poole RM (2001) Clinical importance of changes in chronic pain intensity measured on an 11-point numerical pain rating scale. Pain 94: 149-158

37. Salaffi F, Stancati A, Silvestri CA, Ciapetti A, Grassi W (2004) Minimal clinically important changes in chronic musculoskeletal pain intensity measured on a numerical rating scale. Eur J Pain 8: 283-291.

38. Tönnis D (1990) [Diagnosis and therapy of hip dysplasia in the older child]. Z Orthop Ihre Grenzgeb 128: 369-372. 